\title{
Effects of Cage Pocket Shapes on Dynamics of Angular Contact Ball Bearings
}

\author{
Shijin Chen ${ }^{1)^{*}}$, Xiaoyang $\mathrm{Chen}^{1)}$, Qiqi Shuai ${ }^{1)}$ and Jiaming $\mathrm{Gu}^{2)}$ \\ ${ }^{1)}$ Department of Mechatronic Engineering and Automation, Shanghai University, No.333 Nanchen Road, Shanghai 200072, China \\ 2) Shanghai Tian An Bearing Co. Ltd, No.4399 Yindu Road, Shanghai 201108, China \\ *Corresponding author: Shijin Chen (1093526720@qq.com)
}

Manuscript received 05 August 2020; accepted 29 September 2020; published 15 November 2020

\begin{abstract}
The dynamic models of spherical and cylindrical pocket cages are established based on the dynamic wear simulation model of angular contact ball bearings, and the predicted results are in reasonable agreement with the experimental observations. In this paper, the effects of cage pocket shapes on dynamics of angular contact ball bearings in different pocket clearance are studied based on the established model. It is found that the whirl range of the cylindrical pocket cage is limited by guiding ring, and for spherical pocket cage is limited by balls. And the cage motion of spherical pocket is more stable than that of cylindrical pocket. The stability of the cage is positively related to the stability of the ball's distribution. Meanwhile, the axial swing range of the cage is related to the angle of the ball/cage pocket collision point. In addition, due to the sliding between the balls and the raceways, the bearing friction moment of the spherical pocket cage is larger, and the bearing friction moment of the cylindrical pocket cage is highly transient due to the unstable movement of the cage.
\end{abstract}

\section{Keywords}

angular contact ball bearing, dynamics, cage pocket shapes, stability, moment

\section{Introduction}

With the development of aerospace and equipment manufacturing, higher requirements are placed on the accuracy, life and reliability of rolling bearings for key basic components. The dynamic performance of high-speed rolling bearings, especially the stability of the cage, has attracted much more attention. In 1965, Kingsbury [1] first discovered the relationship between the movement and the moment fluctuations of the ball bearing cage. It was thought that the ball/cage pocket friction force drives the cage whirl, and the unstable cage whirl leads to moment fluctuate and squeal. In 1971, Walters [2] first established the dynamic model of a high-speed ball bearing with four degree of-freedom balls and a six degree of-freedom cage, which laid the foundation for the dynamic analysis of rolling bearing cages. Gupta [3-5] developed a complete dynamics model of rolling bearings for all components with 6 degrees of freedom based on Walters's model, which can simulate the transient motion characteristics of bearing components under time-varying conditions, but due to the complexity of the model, the program calculation takes a long time and is easy to diverge. Since then, Meeks [6, 7], Nogi [8], Niu [9], Liu [10], Farshid [11, 12] and many other scholars [13-15] established dynamics models of rolling bearing for their respective working conditions, which provides many useful explorations for the study of cage stability.

It can be seen that many scholars have researched a lot of the factors affecting the stability of the cage, mainly focusing on friction $[6,8,16]$ load $[8,15]$, speed $[10,17,18]$ and clearance ratio $[6,10,19,20]$ (the ratio of pocket clearance to cage/race clearance), but the study of the structure of the cage itself is slightly insufficient. Gupta [19] and Liu [10] studied the effect of the clearance ratio on the stability of the cylindrical pocket cage. The results show that the cage stability is better when the clearance ratio is less than 1. Sathyan [21] studied the influence of square pockets and cylindrical pockets on the bearing friction moment by experiment. It's found that the friction moment of square pocket bearings is more stable. Therefore, from the current literature research, the pocket shape and clearance have great influence on the stability of the cage and the friction moment of the bearing. However, the effects of the cage pocket shapes on the dynamics of the bearing has not been given enough attention in published study. Based on the dynamic wear simulation model of high-speed instrument rotor bearing established by our research group, the dynamic model of angular contact ball bearing considering spherical pocket cage and cylindrical pocket cage is established, the effects of spherical pockets and cylindrical pockets on the cage stability and bearing friction moment under different pocket clearances are investigated. 


\section{Modeling and verification}

\subsection{The General model}

The dynamic simulation models of spherical and cylindrical pocket cages are established based on the dynamic wear simulation model of angular contact ball bearings of our group $[22,23]$. And the details of the interaction between the balls and rings are in Refs [22]. Furthermore, in order to study the effects of cage pocket shapes on dynamics of angular contact ball bearings, the interaction between ball and different cage types was comprehensively considered in this paper, and the normal force and the tangential force is calculated by Hertz contact theory and Coulomb friction law, respectively. Once the force and moment of the bearing parts are obtained, the motion differential equations of each part can be established and solved by the variable-step 4th-order Runge-Kutta method.

\subsubsection{Ball/cylindrical pocket cage interaction}

The ball/cylindrical pocket cage interaction is shown in Fig. 1. The position vector $r_{\mathrm{bc}}^{\mathrm{i}}$ of the ball center $O_{\mathrm{b}}$ relative to cage center $\mathrm{O}_{\mathrm{c}}$ in the inertial frame can be written as

$$
r_{\mathrm{bc}}^{\mathrm{i}}=r_{\mathrm{b}}^{\mathrm{i}}-r_{\mathrm{c}}^{\mathrm{i}}
$$

where $r_{\mathrm{b}}^{\mathrm{i}}$ and $r_{\mathrm{c}}^{\mathrm{i}}$ are the position vectors of the geometric center of the ball and cage in the inertial frame.

Thus, the position vector $r_{\mathrm{bc}}^{\mathrm{c}}$ in the cage frame is

$$
r_{\mathrm{bc}}^{\mathrm{c}}=T_{\mathrm{ic}} r_{\mathrm{bc}}^{\mathrm{i}}
$$

where $T_{\mathrm{ic}}=\boldsymbol{T}\left(\varphi_{\mathrm{c} 1}, \varphi_{\mathrm{c} 2}, \varphi_{\mathrm{c} 3}\right)$ is the transformation matrix from the inertial frame to the cage frame. And $\varphi_{\mathrm{c} 1}, \varphi_{\mathrm{c} 2}$ and $\varphi_{\mathrm{c} 3}$ are the attitude angles of the cage. In addition, The calculation rule of $T\left(\varphi_{\mathrm{c} 1}, \varphi_{\mathrm{c} 2}, \varphi_{\mathrm{c} 3}\right)$ can be found in the literature [24].

In the cage frame, the position vector of the $j$ th pocket center $O_{\mathrm{p}}$ to the cage center $O_{\mathrm{c}}$ is

$$
r_{\mathrm{pc}}^{\mathrm{c}}=\left[0,-\frac{d_{\mathrm{m}}}{2} \sin \theta_{\mathrm{p}}, \frac{d_{\mathrm{m}}}{2} \cos \theta_{\mathrm{p}}\right]^{\mathrm{T}}
$$

where $\theta_{p}=\frac{2 \pi(j-1)}{z}$ is the azimuth angle of the $j$ th pocket in the cage frame, and $d_{\mathrm{m}}$ is the pitch diameter of the bearing.

Then, the position vector $r_{\mathrm{bp}}^{\mathrm{p}}$ of the ball center $O_{\mathrm{b}}$ relative to cage pocket center $O_{\mathrm{p}}$ in pocket frame is

$$
r_{\mathrm{bp}}^{\mathrm{p}}=T_{\mathrm{cp}}\left(r_{\mathrm{bc}}^{\mathrm{c}}-r_{\mathrm{pc}}^{\mathrm{c}}\right)
$$

where $T_{\mathrm{cp}}=\boldsymbol{T}\left(\theta_{\mathrm{p}}, 0,0\right)$ is the transformation matrix from the cage frame to pocket frame.

The angle of the ball/cylindrical pocket collision point $O_{\mathrm{g}}$ in the pocket frame is

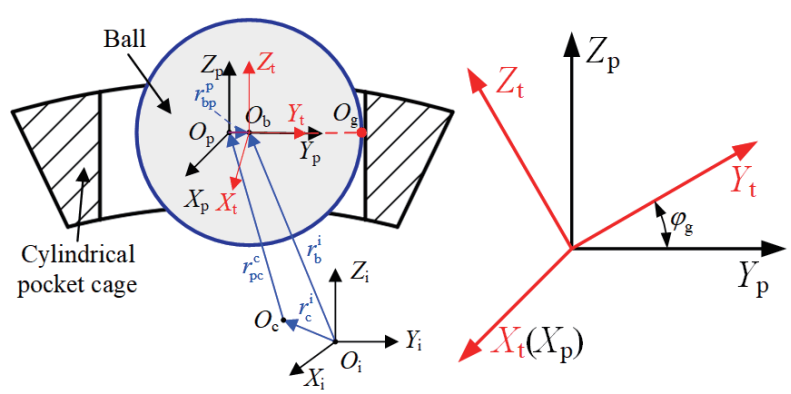

Fig. 1 Interaction between the ball and the cylindrical pocket cage

$$
\phi_{\mathrm{g}}=\arctan \left(\frac{-r_{\mathrm{bp} 1}^{\mathrm{p}}}{r_{\mathrm{bp} 2}^{\mathrm{p}}}\right)
$$

where $r_{\mathrm{bp} 1}^{\mathrm{p}}$ and $r_{\mathrm{bp} 2}^{\mathrm{p}}$ are components of the vector $r_{\mathrm{bp}}^{\mathrm{p}}$.

The position vector of the ball center $O_{b}$ relative to cage pocket center $O_{\mathrm{p}}$ in contact frame can be obtained as

$$
r_{\mathrm{bp}}^{\mathrm{g}}=T_{\mathrm{pg}} r_{\mathrm{bp}}^{\mathrm{p}}
$$

where $T_{\mathrm{pg}}=T\left(0,0, \varphi_{\mathrm{g}}\right)$ is the transformation matrix from the pocket frame to contact frame.

Therefore, the contact deformation between the ball and the cylindrical pocket is

$$
\delta_{\mathrm{bp}}=\sqrt{r_{\mathrm{bp} 1}^{\mathrm{g} 2}+r_{\mathrm{bp} 2}^{\mathrm{g} 2}}-\left(D_{\mathrm{p}}-D_{\mathrm{w}}\right) / 2
$$

where $r_{\mathrm{bp} 1}^{\mathrm{g}}$ and $r_{\mathrm{bp} 2}^{\mathrm{g}}$ are components of $r_{\mathrm{bp}}^{\mathrm{g}}, D_{\mathrm{p}}$ and $D_{\mathrm{w}}$ are the diameter of the pocket and the ball, respectively.

And the contact force between the ball and the cylindrical pocket is calculated according to the Hertz theory as follows:

$$
Q_{\mathrm{c}}=K_{\mathrm{bc}} \delta_{\mathrm{bp}}^{1.5}
$$

where $K_{\mathrm{bc}}$ is the load-deformation coefficient between the ball and the cylindrical pocket.

In the ball and pocket contact frame, the position vector of the contact point $O_{g}$ relative to the ball center $O_{b}$ is:

$$
r_{\mathrm{gb}}^{\mathrm{g}}=\left[0, \frac{D_{\mathrm{w}}}{2}, 0\right]^{\mathrm{T}}
$$

In the cage frame, the position vector of the contact point $O_{g}$ relative to the cage center $O_{\mathrm{c}}$ is:

$$
r_{\mathrm{gc}}^{\mathrm{c}}=\boldsymbol{T}_{\mathrm{cg}}^{-1} r_{\mathrm{gb}}^{\mathrm{g}}+\boldsymbol{r}_{\mathrm{bc}}^{\mathrm{c}}
$$

where $T_{\mathrm{cg}}=T_{\mathrm{pg}} T_{\mathrm{cp}}$ is the transformation matrix of the cage frame to the contact frame.

In addition, in the ball and the pocket contact frame, the velocities $v_{\mathrm{b}}^{\mathrm{g}}$ and $v_{\mathrm{c}}^{\mathrm{g}}$ of the ball and the cage at the contact point can be calculated as:

$$
\begin{aligned}
& v_{\mathrm{b}}^{\mathrm{g}}=T_{\mathrm{ag}} \omega_{\mathrm{b}}^{\mathrm{a}} \times r_{\mathrm{gb}}^{\mathrm{g}} \\
& v_{\mathrm{c}}^{\mathrm{g}}=T_{\mathrm{ig}}\left(v_{\mathrm{c}}^{\mathrm{i}}+\left(T_{\mathrm{ic}}^{-1} \omega_{\mathrm{c}}^{\mathrm{c}}-\left[\dot{\Psi}_{j}, 0,0\right]^{\mathrm{T}}\right) \times\left(T_{\mathrm{ic}}^{-1} r_{\mathrm{gc}}^{\mathrm{c}}\right)\right)
\end{aligned}
$$

where $T_{\mathrm{ag}}=T_{\mathrm{ig}} T_{\mathrm{ia}}^{-1}$ is the transformation matrix from the azimuth frame to the contact frame and $T_{\mathrm{ig}}=T_{\mathrm{cg}} \boldsymbol{T}_{\mathrm{ic}}$ is the transformation matrix from the inertial frame to the contact frame, $\omega_{\mathrm{b}}^{\mathrm{a}}$ is the angular speed of the ball.

The sliding velocity of the cage relative to the ball at the contact center is

$$
v_{\mathrm{cb}}^{\mathrm{g}}=v_{\mathrm{c}}^{\mathrm{g}}-v_{\mathrm{b}}^{\mathrm{g}}
$$

Then, the sliding speed $V_{\mathrm{cb}}$ is

$$
V_{\mathrm{cb}}=\sqrt{\left(v_{\mathrm{cb} 1}\right)^{2}+\left(v_{\mathrm{cb} 3}\right)^{2}}
$$

where $v_{\mathrm{cb} 1}$ and $v_{\mathrm{cb} 3}$ are components of $\boldsymbol{v}_{\mathrm{cb}}^{\mathrm{g}}$.

The tangential force $F_{\mathrm{tc}}$ is obtained by

$$
F_{\mathrm{tc}}=\mu_{\mathrm{c}} Q_{\mathrm{c}}
$$

where $\mu_{\mathrm{c}}$ is the friction coefficient between the ball and the cage pocket.

The components of the tangential force along the major and minor axis are determined by the sliding velocity.

$$
\begin{aligned}
& F_{\mathrm{tcx}}=-F_{\mathrm{tc}} \sin \varphi_{\mathrm{cb}} \\
& F_{\mathrm{tcz}}=F_{\mathrm{tc}} \cos \varphi_{\mathrm{cb}}
\end{aligned}
$$


where $\phi_{\mathrm{cb}}=\arctan \left(\frac{-v_{\mathrm{cb} 1}}{v_{\mathrm{cb} 3}}\right)$ is the angle between the velocity vector $v_{\mathrm{cb}}$ and the $Z_{\mathrm{g}}$ axis of contact frame.

The force vector $\boldsymbol{F}_{\mathrm{cb}}^{\mathrm{g}}$ and moment vector $\boldsymbol{M}_{\mathrm{cb}}^{\mathrm{g}}$ of the cage acts on the ball in the contact frame are given as

$$
\begin{aligned}
& \boldsymbol{F}_{\mathrm{cb}}^{\mathrm{g}}=\left[F_{\mathrm{tcx}},-Q_{\mathrm{c}}, F_{\mathrm{tcz}}\right]^{\mathrm{T}} \\
& \boldsymbol{M}_{\mathrm{cb}}^{\mathrm{g}}=\boldsymbol{r}_{\mathrm{gb}}^{\mathrm{g}} \times \boldsymbol{F}_{\mathrm{cb}}^{\mathrm{g}}
\end{aligned}
$$

And the force vector $F_{j \mathrm{bc}}^{\mathrm{g}}$ of the ball acts on the cage in the contact frame is

$$
F_{\mathrm{jbc}}^{\mathrm{g}}=-\boldsymbol{F}_{\mathrm{cb}}^{\mathrm{g}}
$$

The moment vector $\boldsymbol{M}_{\mathrm{jbc}}^{\mathrm{c}}$ of the ball acts on the cage in the cage frame is

$$
\boldsymbol{M}_{\mathrm{jbc}}^{\mathrm{c}}=\boldsymbol{r}_{\mathrm{gc}}^{\mathrm{c}} \times\left(-\boldsymbol{T}_{\mathrm{cg}}^{-1} \boldsymbol{F}_{\mathrm{cb}}^{\mathrm{g}}\right)
$$

Thus, the interaction force and moment between the ball and the cylindrical pocket cage can be calculated.

\subsubsection{Ball/spherical pocket cage interaction}

As shown in Fig. 2, due to the complexity of the spherical pocket boundary, the interaction between the ball and the spherical pocket cage is more complicated than that of the cylindrical pocket. Therefore, it is necessary to calculate the position of the collision point $O_{\mathrm{g}}$ between the ball and the cage pocket. When $\varphi_{\mathrm{c} 2}<\varphi_{\mathrm{g}}<\varphi_{\mathrm{c} 1}$, the collision point $O_{\mathrm{g}}$ is on the arc of the spherical pocket as shown in Fig. 2a, otherwise, the collision point $O_{\mathrm{g}}$ is on the spatial intersection curve between the spherical surface and the outer (or inner) cylindrical surface as shown in Fig. 2b. The equations of spatial intersection curves in pocket frame are

$$
\begin{aligned}
& \left\{\begin{array}{c}
\left(y-y_{j}\right)^{2}+\left(z-z_{j}\right)^{2}=\left(\frac{D_{\mathrm{c}}}{2}\right)^{2} \quad-\frac{B_{\mathrm{c}}}{2}<x<\frac{B_{\mathrm{c}}}{2} \\
x^{2}+y^{2}+z^{2}=\left(\frac{D_{\mathrm{p}}}{2}\right)^{2}
\end{array}\right. \\
& \left\{\begin{array}{c}
\left(y-y_{j}\right)^{2}+\left(z-z_{j}\right)^{2}=\left(\frac{d_{\mathrm{c}}}{2}\right)^{2} \quad-\frac{B_{\mathrm{c}}}{2}<x<\frac{B_{\mathrm{c}}}{2} \\
x^{2}+y^{2}+z^{2}=\left(\frac{D_{\mathrm{p}}}{2}\right)^{2}
\end{array}\right.
\end{aligned}
$$

where $y_{j}, z_{j}$ represent the coordinates of the cage center in the pocket frame, $D_{c}, d_{c}$ represents the outer diameter and inner diameter of the cage, respectively, and $B_{c}$ is the cage width.

In order to obtain the coordinate value of the point $O_{\mathrm{cg}}$, the angle $\varphi_{\mathrm{bp}}$ between the vector $r_{\mathrm{bp}}^{\mathrm{p}}$ and the $X_{\mathrm{p}}$ axis is obtained as following.

$$
\varphi_{b p}=\left\{\begin{array}{cc}
\arctan \left(\frac{r_{\mathrm{bp} 2}^{\mathrm{p}}}{r_{\mathrm{bp} 1}^{\mathrm{p}}}\right) & r_{\mathrm{bp} 1}^{\mathrm{p}}>0 \\
\pi-\arctan \left(\frac{r_{\mathrm{bp} 2}^{\mathrm{p}}}{r_{\mathrm{bp} 1}^{\mathrm{p}}}\right) & r_{\mathrm{bp} 1}^{\mathrm{p}}<0
\end{array}\right.
$$

Therefore, the coordinate value of the point $O_{\mathrm{cg}}$ satisfies the following formula

$$
\frac{\mathrm{y}}{\mathrm{x}}=\tan \left(\phi_{b p}\right)
$$

(a)

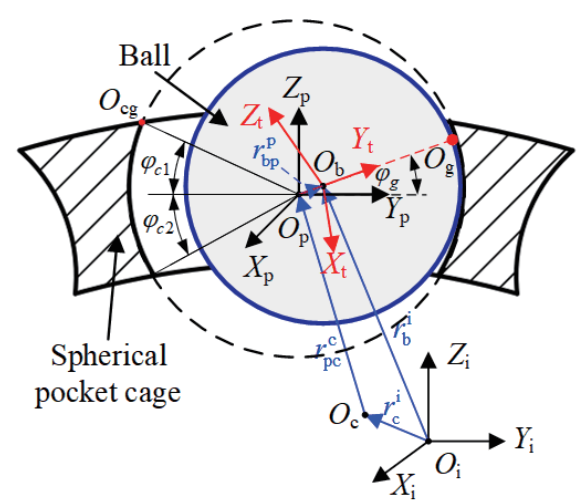

(b)

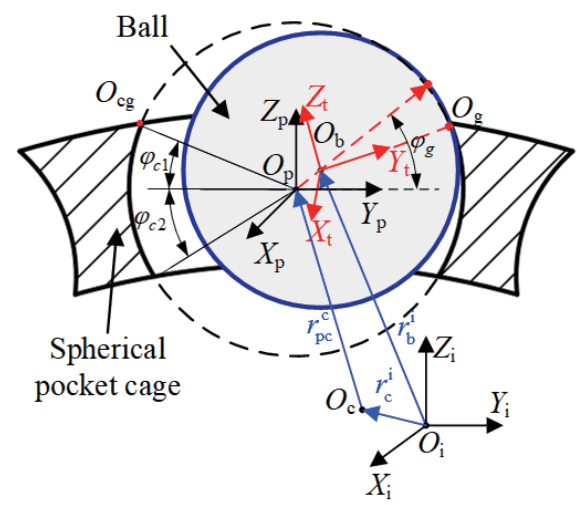

(c)
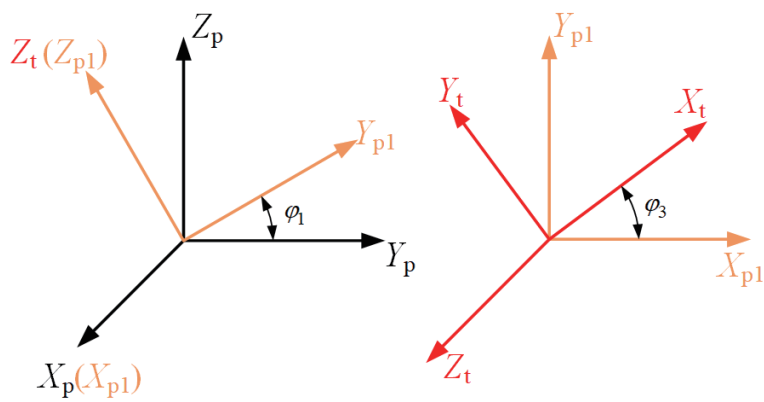

Fig. 2 Interaction between the ball and the spherical pocket cage (a) $O_{g}$ on pocket surface (b) $O_{g}$ on the boundary line (c) $O_{g}$ Coordinate conversion

When $r_{\mathrm{bp3}}^{\mathrm{p}}>0$, Eq. (24) is combined with Eq. (21) to obtain the coordinate value of the point $O_{\mathrm{cg},}$ otherwise, it is combined with Eq. (22). In addition, it may be noted that once the coordinate values of point $O_{\mathrm{cg}}$ are obtained, that is, the vector $\boldsymbol{r}_{\mathrm{gp}}^{\mathrm{p}}$ of point $O_{\mathrm{cg}}$ to cage pocket center is obtained. Then, $\varphi_{\mathrm{g}} \varphi_{\mathrm{c} 1}$ and $\varphi_{\mathrm{c} 2}$ can be calculated as follows

$$
\begin{aligned}
& \varphi_{g}=\arctan \left(\frac{r_{\mathrm{bp} 3}^{\mathrm{p}}}{\sqrt{r_{\mathrm{bp} 1}^{\mathrm{p}}+r_{\mathrm{bp} 2}^{\mathrm{p} 2}}}\right) \\
& \varphi_{c 1}=\arctan \left(\frac{r_{\mathrm{gp} 3}^{\mathrm{p}}}{\sqrt{r_{\mathrm{gp} 1}^{\mathrm{p}}+r_{\mathrm{gp} 2}^{\mathrm{p} 2}}}\right) \quad r_{\mathrm{gp} 3}^{\mathrm{p}}>0 \\
& \varphi_{c 2}=\arctan \left(\frac{r_{\mathrm{gp} 3}^{\mathrm{p}}}{\sqrt{r_{\mathrm{gp} 1}^{\mathrm{p}}+r_{\mathrm{gp} 2}^{\mathrm{p} 2}}}\right) \quad r_{\mathrm{gp} 3}^{\mathrm{p}}<0
\end{aligned}
$$


When $\varphi_{\mathrm{c} 2}<\varphi_{\mathrm{g}}<\varphi_{\mathrm{c} 1}$, the ball/cage pocket collision point $O_{\mathrm{g}}$ is as shown in Fig. 2a, and the angle of the collision point $O_{8}$ between the ball and the spherical pocket in the pocket frame are

$$
\begin{aligned}
& \varphi_{1}=\arctan \left(\frac{r_{\mathrm{bp} 3}^{\mathrm{p}}}{r_{\mathrm{bp} 2}^{\mathrm{p}}}\right) \\
& \varphi_{3}=\arctan \left(\frac{-r_{\mathrm{bp} 1}^{\mathrm{p}}}{\sqrt{r_{\mathrm{bp} 2}^{\mathrm{p}}+r_{\mathrm{bp} 3}^{\mathrm{p}}}}\right)
\end{aligned}
$$

The position vector of the ball center $O_{\mathrm{b}}$ relative to cage pocket center $O_{p}$ in contact frame can be written as

$$
r_{\mathrm{bp}}^{\mathrm{g}}=T_{\mathrm{pg}} r_{\mathrm{bp}}^{\mathrm{p}}
$$

where $T_{\mathrm{pg}}=T\left(\varphi_{1}, 0, \varphi_{3}\right)$ is the transformation matrix from the pocket frame to contact frame.

Therefore, the contact deformation between the ball and the spherical pocket is

$$
\delta_{\mathrm{bp}}=\sqrt{r_{\mathrm{bp} 1}^{\mathrm{g} 2}+r_{\mathrm{bp} 2}^{\mathrm{g} 2}+r_{\mathrm{bp} 3}^{\mathrm{g} 2}}-\left(D_{\mathrm{p}}-D_{\mathrm{w}}\right) / 2
$$

When $\varphi_{\mathrm{g}} \leq \varphi_{\mathrm{c} 2}$ or $\varphi_{\mathrm{g}} \geq \varphi_{\mathrm{c} 1}$, the ball/cage pocket collision point $\mathrm{O}_{\mathrm{g}}$ is as shown in Fig. 2b, the position vector of the contact point $O_{g}$ relative to the ball center $O_{\mathrm{b}}$ in cage frame is:

$$
r_{\mathrm{gb}}^{\mathrm{p}}=r_{\mathrm{gp}}^{\mathrm{p}}-r_{\mathrm{bp}}^{\mathrm{p}}
$$

So, the collision angles are

$$
\begin{gathered}
\varphi_{1}=\arctan \left(\frac{r_{\mathrm{gb} 3}^{\mathrm{p}}}{r_{\mathrm{gb} 2}^{\mathrm{p}}}\right) \\
\varphi_{3}=\arctan \left(\frac{-r_{\mathrm{gb} 1}^{\mathrm{p}}}{\sqrt{r_{\mathrm{gb} 2}^{\mathrm{p}^{2}}+r_{\mathrm{gb} 3}^{\mathrm{p}}}}\right)
\end{gathered}
$$

where $r_{\mathrm{gb} 1}^{\mathrm{p}}$ and $r_{\mathrm{gb} 2}^{\mathrm{p}}$ are components of the vector $\boldsymbol{r}_{\mathrm{gb}}^{\mathrm{p}}$.

The position vector of the contact point $O_{\mathrm{g}}$ relative to the ball center $O_{\mathrm{b}}$ in contact frame can be written as

$$
r_{\mathrm{gb}}^{\mathrm{g}}=T_{\mathrm{pg}} r_{\mathrm{gb}}^{\mathrm{p}}
$$

where $T_{\mathrm{pg}}=T\left(\varphi_{1}, 0, \varphi_{3}\right)$ is the transformation matrix from the pocket frame to contact frame.

Therefore, the contact deformation between the ball and the spherical pocket is

$$
\delta_{\mathrm{bp}}=\sqrt{r_{\mathrm{gb} 1}^{\mathrm{g} 2}+r_{\mathrm{gb} 2}^{\mathrm{g} 2}+r_{\mathrm{gb} 3}^{\mathrm{g} 2}}-D_{w} / 2
$$

Once the contact deformation between the ball and the spherical pocket cage is obtained, the force and moment between the ball and the spherical pocket cage can be calculated in the same way as the cylindrical pocket cage.

\subsection{Experimental verification}

The high-speed angular contact ball bearing cage dynamic characteristic test device designed by our team [25] was used to verify the models. As shown in Fig. 3, motor 1 connects to a shaft through the coupling to drive the inner ring of the test bearing, the motor 2 drives the outer ring of the test bearing through another shaft and the friction wheel. Changing the input frequency of the motors to get variable speed of the inner and outer rings of the bearing, and the inner and outer rings of the bearing can rotate independently. The test angular contact ball bearings were installed in pairs and the axial load was adjusted through the spacers. In addition, both the radial and (a)

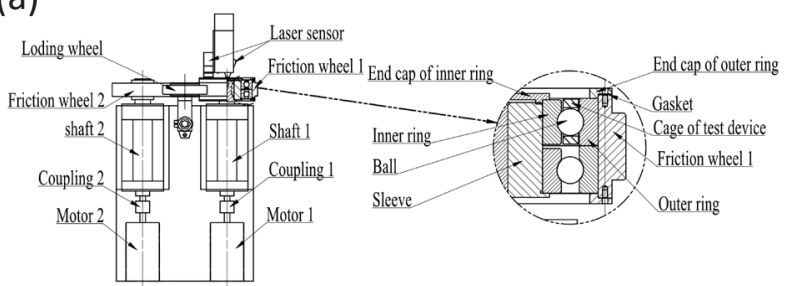

(b)

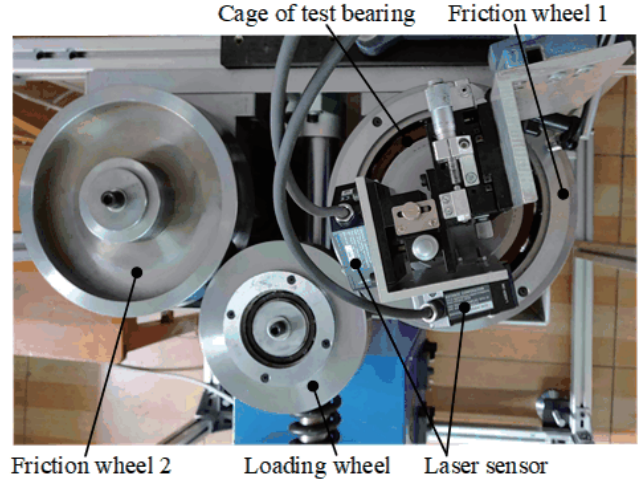

(c)

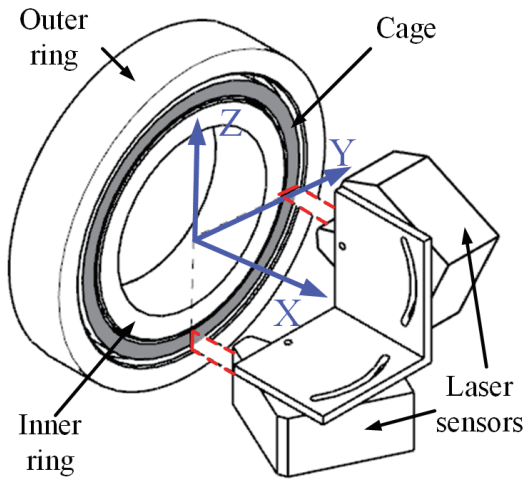

Fig. 3 Drawing of test device (a) Schematic diagram (b) Practicality picture (c) Transducers arrangement

axial displacements of the cage are measured by two vertically arranged laser line displacement sensors to obtain the threedimensional orbit of cage mass center. It should be noted that the cage deformation is not considered, and the detailed measurement principle of its mass center orbit can be found in literature [25]. Figure $3 \mathrm{c}$ shows the arrangement of the sensors and the definition of the coordinate system clearly. It may be noted that the pocket clearance of the spherical pocket cage is $0.8 \mathrm{~mm}$, and other parameters are the same as cylindrical pocket cage in the literature [25]. The bearings were assumed to operate at a shaft speed of $1000 \mathrm{rpm}$ and be subjected to thrust load of $100 \mathrm{~N}$. In order to study the performance of the bearing after it has reached a steady state, only the data after 1 second is given in all the figures in this paper.

Figures $4 \mathrm{a}$ and $4 \mathrm{~b}$ show the three-dimensional mass center orbits of the spherical pocket cage obtained by simulation and experiment, respectively. And for a clearer view of the cage whirl orbit in the $Y Z$ plane and the axial (X-direction) swing range, the figure also shows the projection of the cage mass center in the $Y Z$ plane (black) and the $X Y$ plane (blue), respectively. It can be seen that the whirl orbits of the cages obtained by the experiment and simulation are circular, and the orbit radius is basically the same, and from the projection of the 
$X Y$ plane, it can be clearly seen that the predicted axial swing range of the cage is close to the experiment. In addition, as Fig. $4 \mathrm{c}$ shows that the cage displacement response of simulation is in good agreement with experiment, indicating that the cage whirl speeds are substantially equal. Therefore, the threedimensional mass center orbit and speed of the cage in the simulation and test are in good agreement, indicating that

(a)

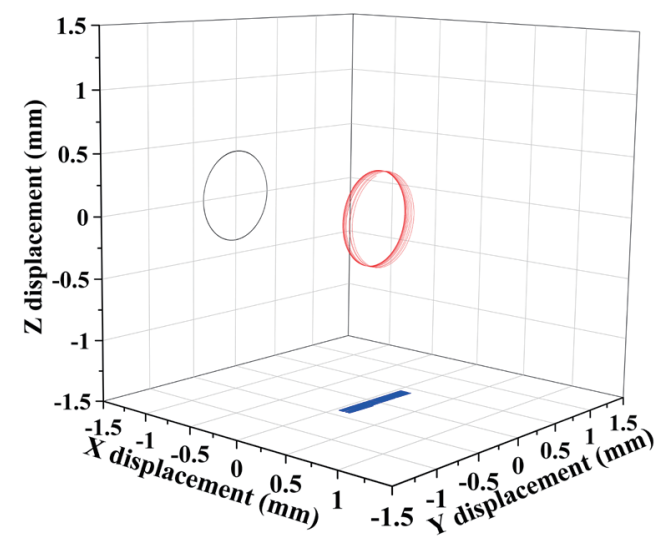

(b)

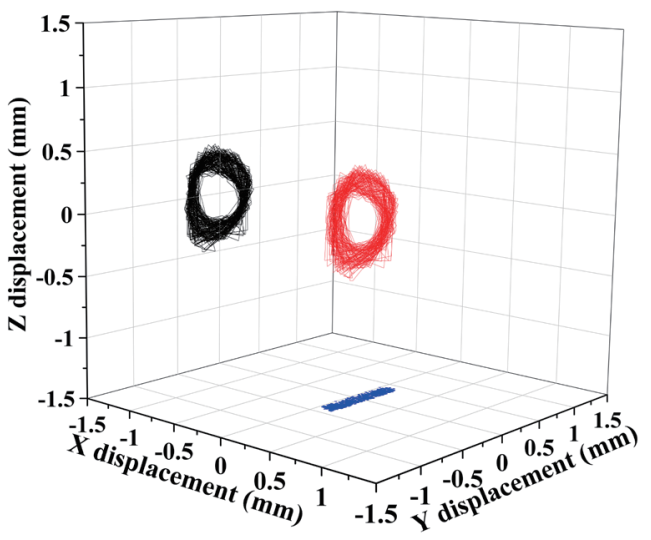

(c)

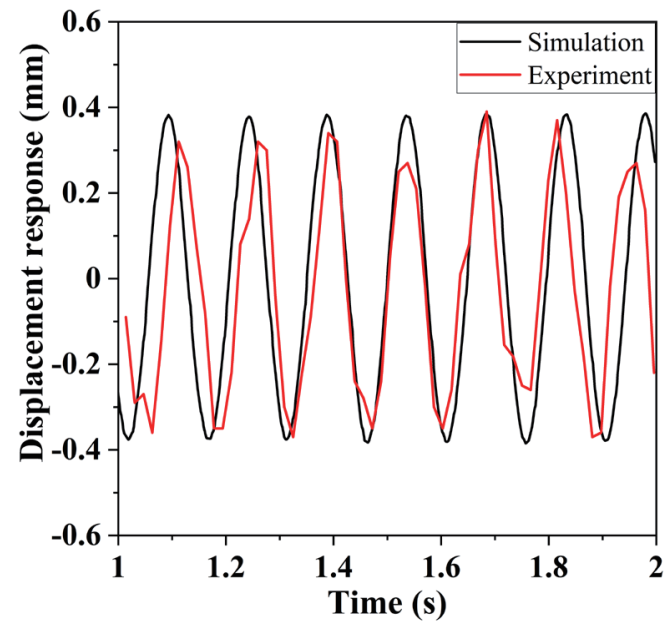

Fig. 4 The spherical pocket cage mass center orbits (a) simulation results (b) experiment results (c) displacement response the cage movement is consistent. Since the cage movement is the result of the combined action of the bearing structure and working conditions, the consistency of the cage movement in the test and simulation verifies the correctness of the simulation model of the spherical pocket cage. Similarly, for a cylindrical pocket cage, the same conclusion can be concluded by Fig. 5 .

(a)

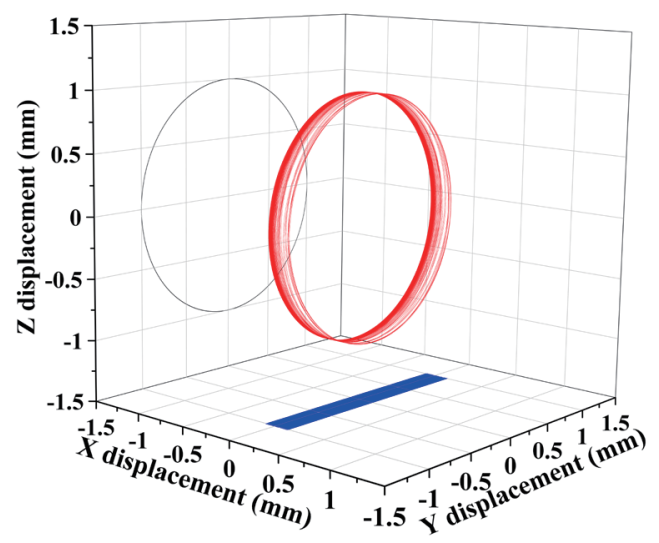

(b)

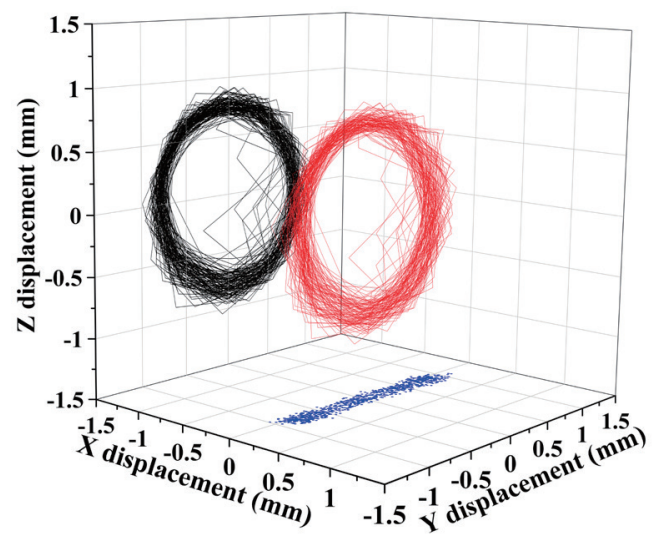

(c)

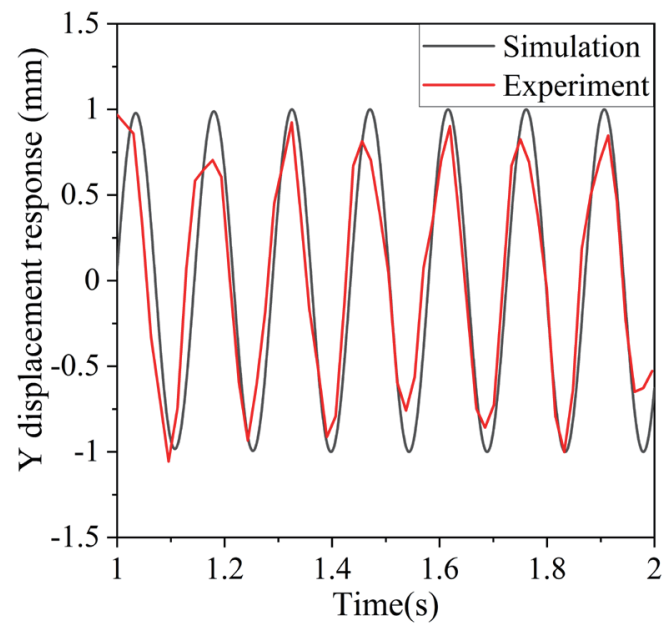

Fig. 5 The cylindrical pocket cage mass center orbits (a) simulation results (b) experiment results (c) displacement response 


\section{Results and discussion}

For a high-speed angular contact ball bearing, the influences of spherical pocket and cylindrical pocket on the cage stability and bearing friction moment are analysed under the operating conditions of $30000 \mathrm{r} / \mathrm{min}$ shaft speed and $7 \mathrm{~N}$ thrust load. In addition, with a cloth Bakelite cage, the cage stability and bearing friction moment as a function of increasing pocket clearance are studied as well. The bearing (1\#) geometry parameters and material properties are listed in Table 1, and the pocket clearance is $0.096 \mathrm{~mm}, 0.135 \mathrm{~mm}$ and $0.24 \mathrm{~mm}$, while the cage/race clearance is always $0.24 \mathrm{~mm}$.
3.1 Influence of different pockets on the stability of the cage

Figures 6 and 7 show the three-dimensional mass center orbit of different pocket type cages under different pocket clearance. It can be seen from Fig. 6 that the whirl orbits of the spherical pocket cage are regular circle under different pocket clearance and the whirl radius are slightly smaller than half of pocket clearance, moreover, the axial swing range of the cage enlarges with the increase of the pocket clearance, but even the largest swing range is small, indicating that the cage is precisely guided by the balls when the cage pocket is spherical. When the pocket is cylindrical, as shown in Fig. 7, as the pocket clearance increases, the three-dimensional mass center orbit of cage is

Table 1 Bearing (1\#) geometry and material properties

\begin{tabular}{llll}
\hline Bearing Bore / mm & 4 & Inner Race Curvature Factor & 0.535 \\
Bearing Outside Diameter / mm & 11 & Outer Race Curvature Factor & 0.585 \\
Pitch Diameter / mm & 7.5 & Cage Inside Diameter / mm & 6.53 \\
Ball Diameter / mm & 2 & Cage Outside Diameter / mm & 8.63 \\
Number of Balls & 7 & Pocket Clearance / mm & $0.096 / 0.135 / 0.24$ \\
Contact Angle / & 20 & Cage/Race Clearance / mm & 0.24 \\
\hline & & Material Properties & \\
Element & Elastic Modulus & Poisson's & Density \\
& $(\mathrm{MPa})$ & Ratio & $\left(\mathrm{g} / \mathrm{cm}^{3}\right)$ \\
\hline Ball and Race & $2.07 \mathrm{e} 5$ & 0.3 & 7.85 \\
Cage & 3000 & 0.38 & 1.27 \\
\hline
\end{tabular}
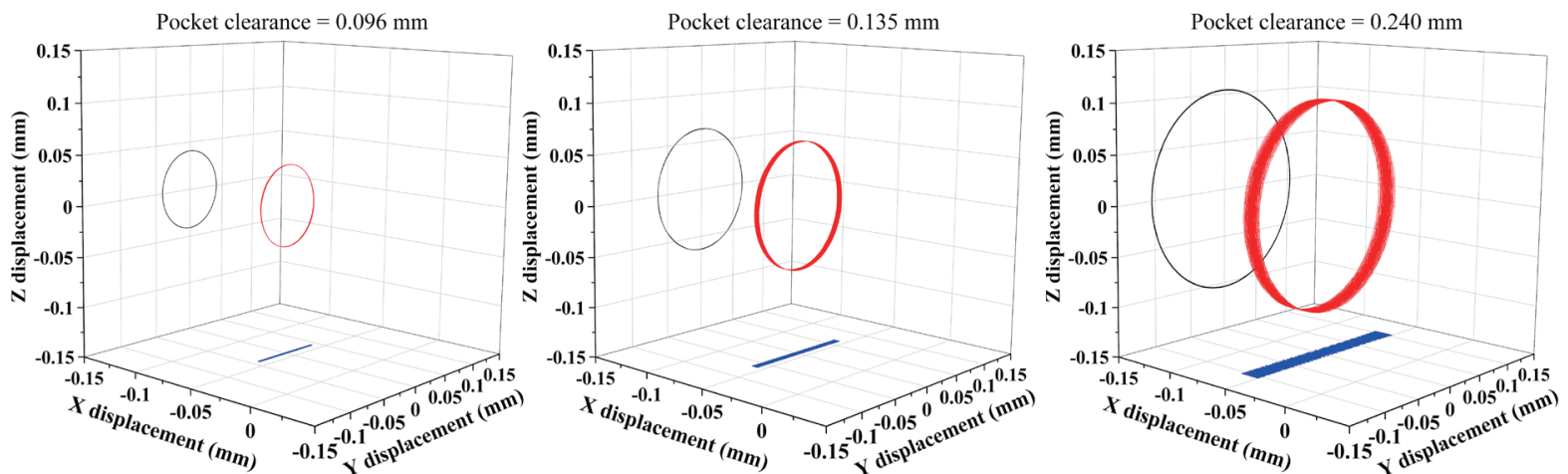

Fig. 6 Whirl orbit of spherical pocket cage in different pocket clearance
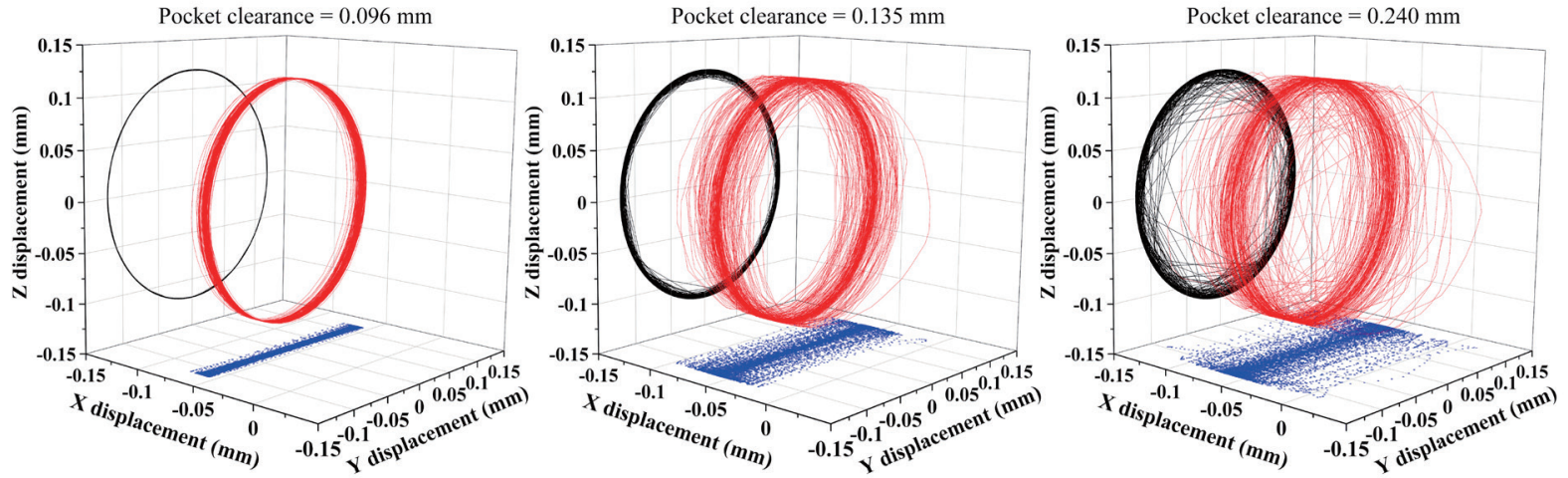

Fig. 7 Whirl orbit of cylindrical pocket cage in different pocket clearance 
gradually disordered for the cage whirl orbit changes from a regular circle to a polygonal orbit, and the axial swing range is significantly increased. Furthermore, unlike the spherical pocket cage, the whirl diameter is equal to cage/race clearance although the pocket clearance is less than the cage/race clearance, which shows that the whirl range of the cylindrical pocket cage is determined by the cage/race clearance rather than the pocket clearance.

Moreover, in order to quantitatively analyse the stability of the cage, the Ghaisas's method [26] was used to describe the stability of the cage by using the velocity deviation ratio (the ratio of the standard deviation of the cage mass center whirl velocity to its mean value):

$$
\sigma_{v}=\frac{\sqrt{\frac{1}{n-1} \sum_{i=1}^{n}\left(v_{i}-\bar{v}\right)^{2}}}{\bar{v}}
$$

where $v_{\mathrm{i}}$ is the cage mass center whirl velocity at each time point and $\bar{v}$ is its mean value; $\sigma_{v}$ is deviation ratio of cage whirl speed. Hence, smaller values of $\sigma_{v}$ correspond to more stable cage motion.

According to the above method, the whirl velocity deviation ratio of the different pocket type cages under different pocket clearance is calculated as shown in Fig. 8. It may be noted that

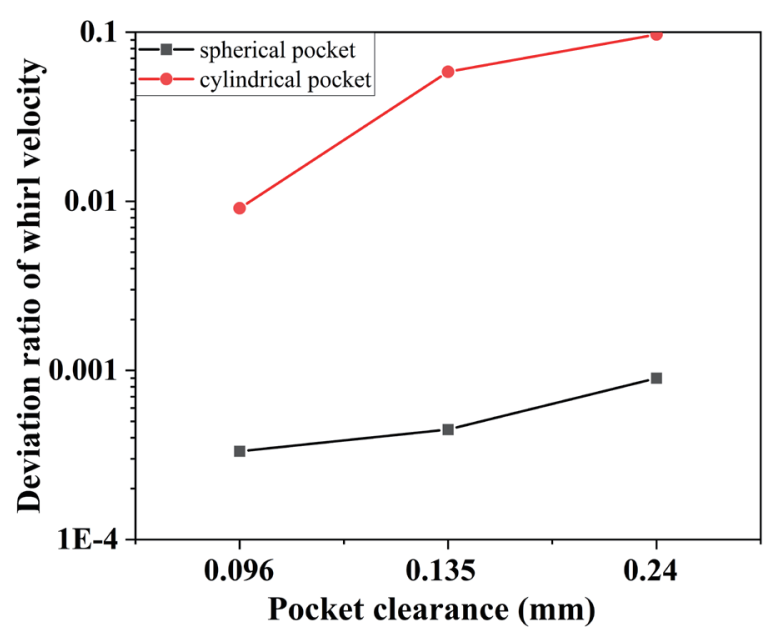

Fig. 8 Deviation ratio of cage whirl velocity since the whirl velocity deviation ratio of the ball pocket cage is much different from that of the cylindrical pocket cage, the vertical axis in Fig. 8 is a logarithmic coordinate. Obviously, with the increase of pocket clearance, the whirl velocity deviation ratio increases in both spherical pocket cage and the cylindrical pocket cage, indicating that large pocket clearance is not conducive to the stability of the cage. In addition, in the given pocket clearance, the whirl velocity deviation of the spherical pocket cage is much smaller than that of the cylindrical pocket cage, which shows that the stability of the spherical pocket cage is much better than that of a cylindrical pocket cage.

\subsubsection{Distribution of the ball spacing}

As Sakaguchi [27] pointed out that the cage whirl state is related to the distribution of the rollers in tapered roller bearing. Therefore, it is tried to explore the relationship between the distribution of the ball spacing and the cage whirl state in the ball bearings. Figure 9 shows the distribution diagram of the ball spacing in the cage, $\Delta \theta$ represents the angular difference between two adjacent balls, $\theta_{0}$ represents the average angle between 7 balls.

Figures 10 and 11 show the distribution of the ball spacing under different pocket clearance of spherical pocket cage and cylindrical pocket cage, respectively, and it is obvious that $\Delta \theta$ is distributed unequally in all cases. In the spherical pocket cage, as shown in Fig. 10, with the increase of pocket clearance, the uneven distribution of the ball and the corresponding whirl

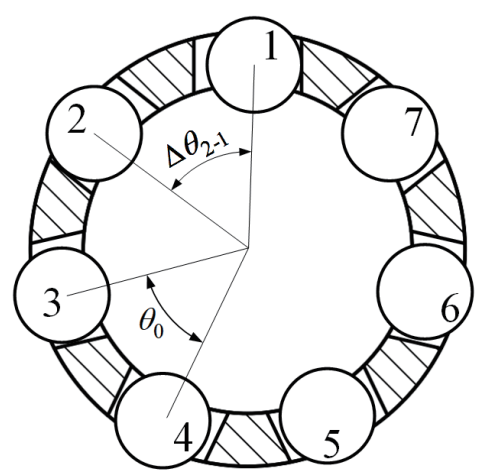

Fig. 9 Distribution diagram of the balls in the cage
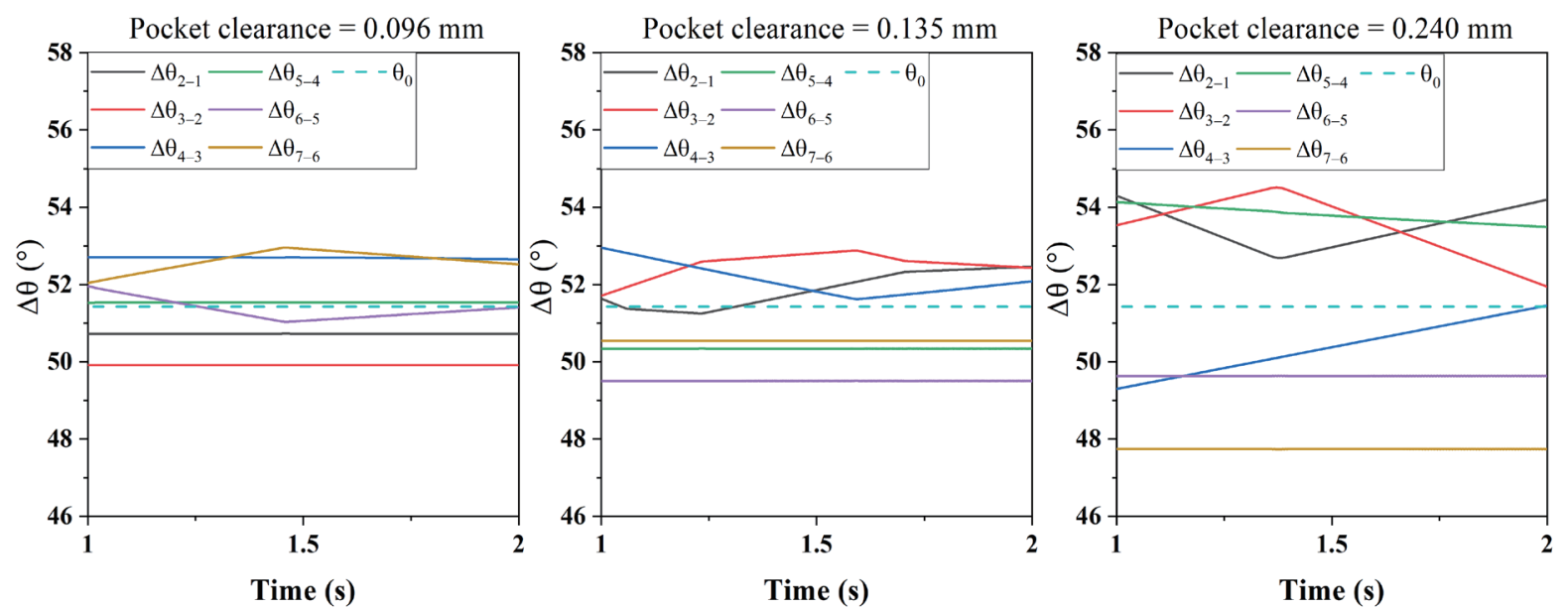

Fig. 10 Spacing between balls in spherical pocket cage in different pocket clearance 

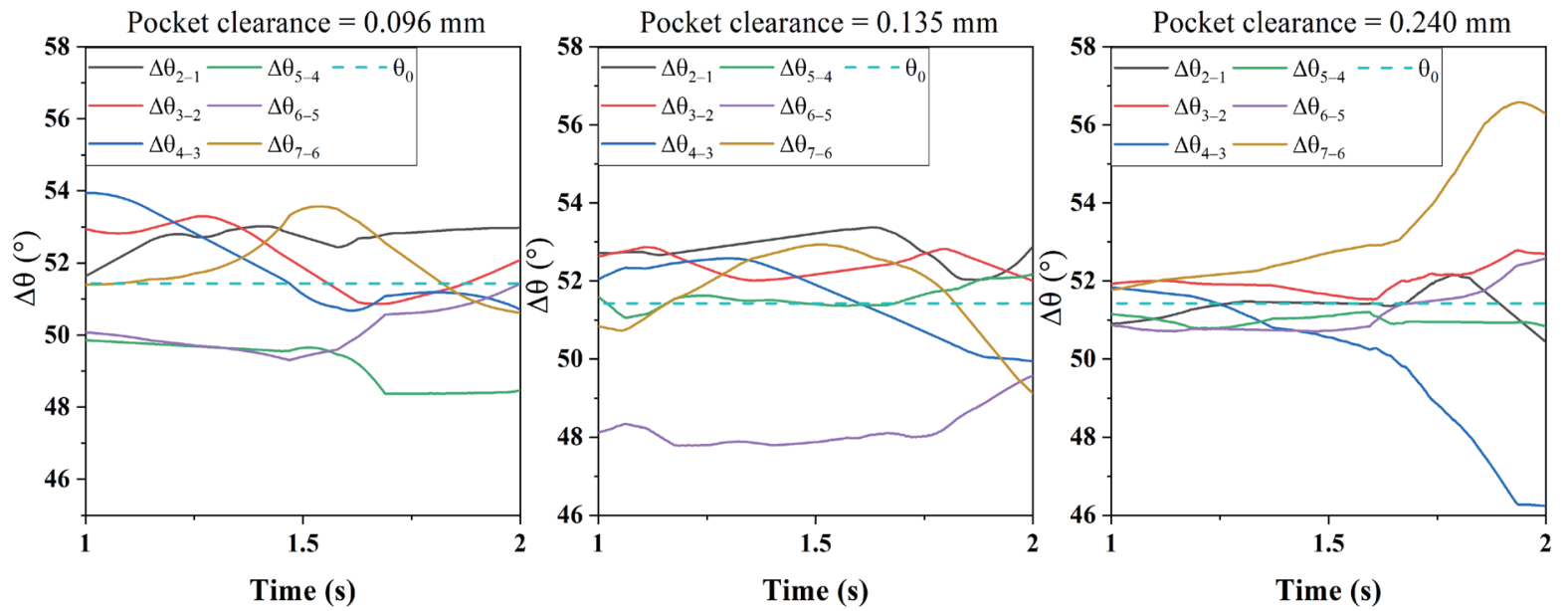

Fig. 11 Spacing between balls in cylindrical pocket cage in different pocket clearance

radius (shown in Fig. 6) of the cage also increases, it may be as explained by Sakaguchi [27], unequal steady distribution of rolling elements is important to increase the cage movable distance and consequently to increase the whirl radius. When the pocket is cylindrical, as the pocket clearance increases, the $\Delta \theta$ changes more and more frequent as shown in Fig. 11, and the corresponding cage stability (shown in Fig. 8) gradually deteriorates. So, it may be concluded that the unequal steady distribution of the spacing between balls is an important characteristic for stable conditions of bearings. In addition, by comparing the cage stability and $\Delta \theta$ of the spherical pocket cage and the cylindrical pocket cage, it can be seen clearly that $\Delta \theta$ changes faster in cylindrical pocket cage than that in the more stable spherical pocket cage in all of pocket clearance, which verifies the above relationship between $\Delta \theta$ and cage stability.

\subsubsection{Angle of ball/cage collision point}

In the spherical pocket cage, the angle of the ball/cage pocket collision point have a great influence on the cage stability for the cage only interacts with the ball. The angle of the ball/ cage collision point is defined as shown in Fig. 12, when the angle is $0^{\circ}$, the ball push cage rotates. When the angle is $180^{\circ}$, the ball hinders the rotation of the cage.

Figures 13 and 14 show the angles of the ball/cage pocket collision points in different pocket clearance of the spherical pocket cage and the cylindrical pocket cage, respectively. As shown in Fig. 13, when the cage pocket is spherical, the angle of ball/cage pocket collision point is $0^{\circ}$ or $180^{\circ}$, the axial component of the ball/cage pocket collision force is very small, so the cage has a small axial swing range and is very stable

\section{Direction of rotation}

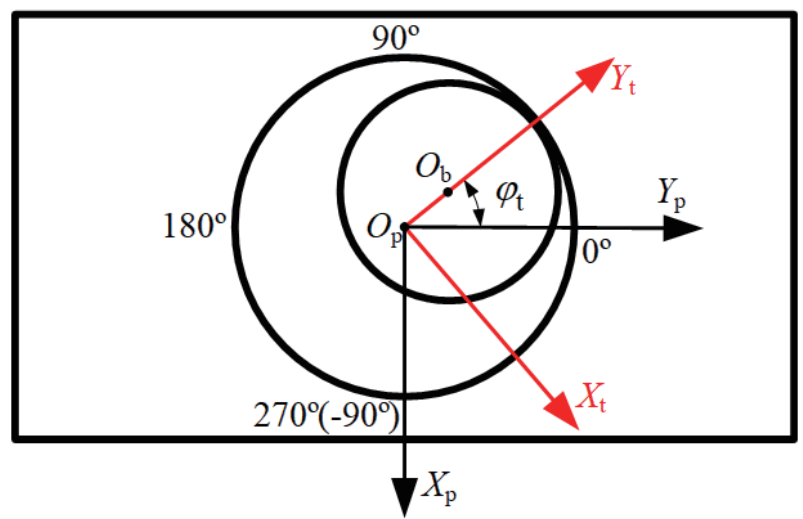

Fig. 12 Angle of ball/cage pocket collision point definition
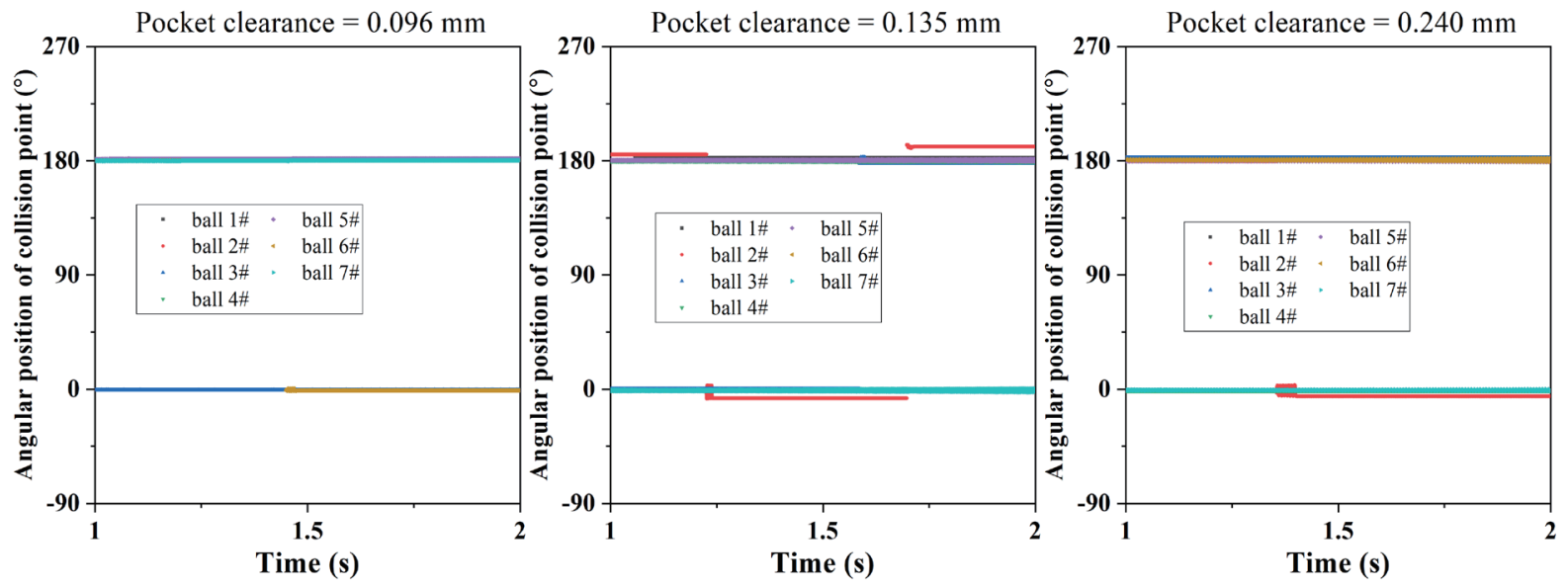

Fig. 13 Angle of ball/spherical pocket cage collision point 

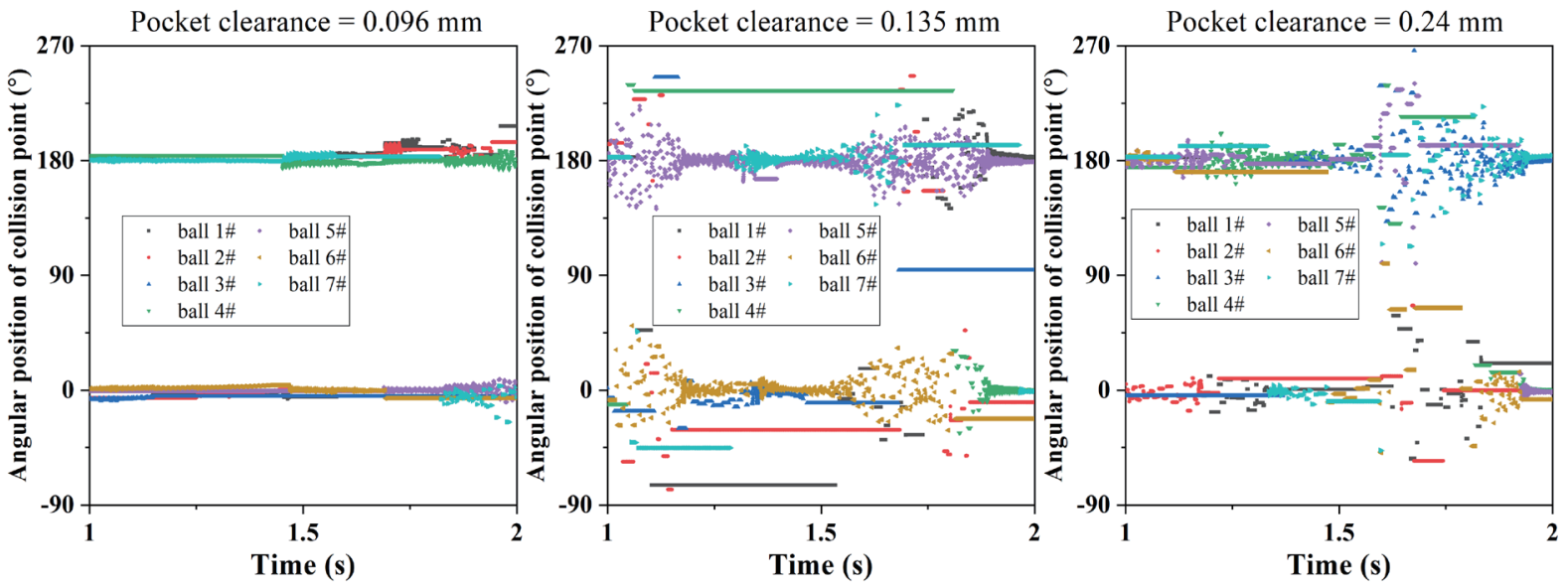

Fig. 14 Angle of ball/cylindrical pocket cage collision point

(shown in Fig. 6). When the cage pocket is cylindrical, as shown in Fig. 14, as the pocket clearance increases, the uncertainty of ball/cage pocket collision point angle gradually increases, and the angle distribution range also increases gradually, which would result the direction of ball/cage pocket collision force change frequently, and further lead a wide axial swing range of the cylindrical pocket cage and the cage instability (shown in Fig. 7).

\subsection{Influence of different pockets on bearing friction moment}

There are many factors affecting the friction moment of the bearing. In this section, the friction moment caused by the elastic hysteresis, the differential sliding and the spin sliding between the ball and the raceway, the sliding friction between the cage and the ball and the guide land is considered. Reference [28] gives the calculation method of friction moment caused by elastic hysteresis. The friction moment caused by sliding is calculated according to power loss, as follows

$$
M=\frac{\mu Q V}{\omega_{\mathrm{i}}}
$$

where $M$ is the friction moment caused by the sliding between the bearing parts, $\mu, Q$ and $V$ is the friction coefficient, contact load and sliding speed between the bearing parts respectively, and $\omega_{\mathrm{i}}$ is inner ring angular speed.

Figures 15 and 16 show the bearing friction moment caused by the elastic hysteresis, the sliding friction between the ball and the raceway, the sliding friction between the cage and the ball and the guide land in spherical pocket and cylindrical pocket cage. Clearly, the pocket clearance has a great influence on bearing friction moment of the cylindrical pocket cage and has little effect on the friction moment of the spherical pocket cage. The bearing friction moment of the spherical pocket cage is very stable and is maintained at $0.11 \mathrm{~N} \cdot \mathrm{mm}$ in the given clearance, while the average value of the friction moment of the cylindrical pocket cage is much smaller than $0.11 \mathrm{~N} \cdot \mathrm{mm}$ but fluctuate violently. Furthermore, in spherical pocket cage, the bearing friction moment is mainly caused by the sliding between the ball and the inner ring, outer ring and the cage, which is mainly consisted of the sliding between the ball and the inner ring, the outer ring and the cage, which account for $40.3 \%$, 35.5\%, and $20.1 \%$, respectively. For the cylindrical pocket cage, the friction moment caused by the sliding between the ball and the inner and outer rings contributes the base value of the bearing friction moment, and the peak of the fluctuation is mainly composed of the friction moment between the cage and the guide ring or the ball.

As shown in Eq. (38), the friction moment is mainly related to the friction coefficient $\mu$, the pressure $Q$, the sliding speed $V$, and the inner ring angular velocity $\omega_{\mathrm{i}}$. In this paper, the friction coefficient $\mu$ and the inner ring angular velocity $\omega_{\mathrm{i}}$ are constant values, so the friction moment is proportional to the pressure $Q$, sliding speed $V$. Moreover, the cage pocket shape has little effect on the pressure, thus the friction moment between the ball and
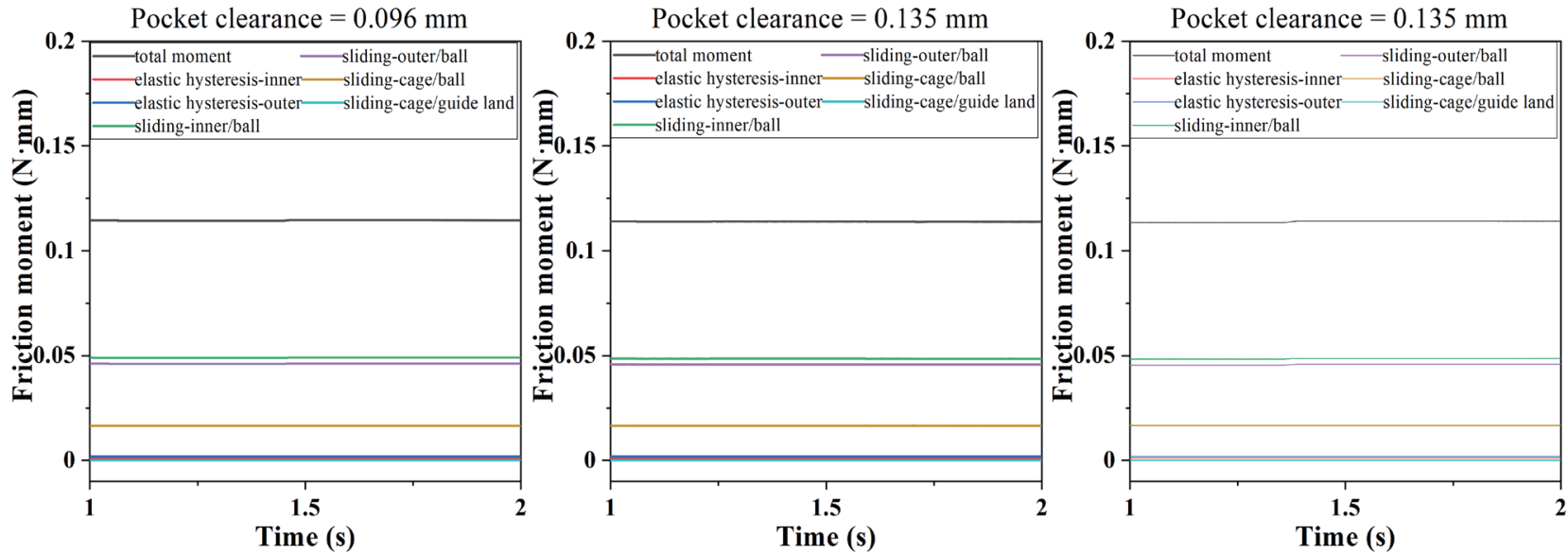

Fig. 15 The bearing friction moment of spherical pocket cage 

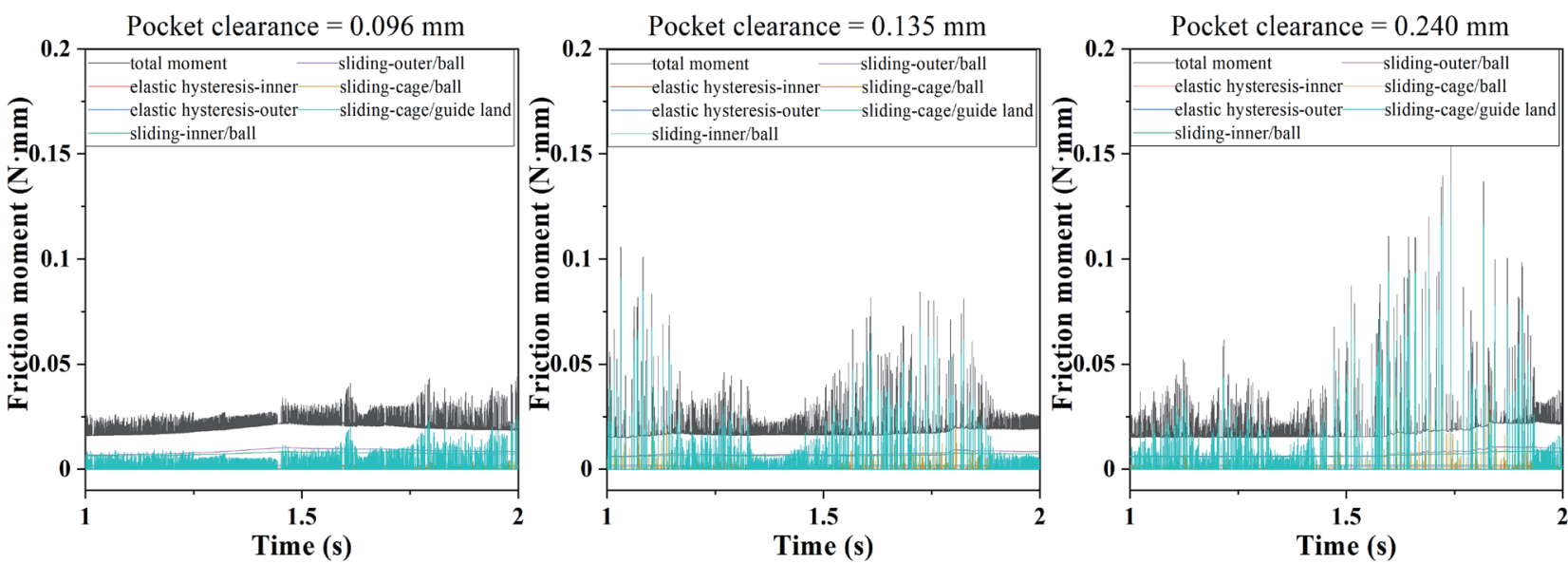

Fig. 16 The bearing friction moment of cylindrical pocket cage

the raceway is mainly affected by their relative sliding velocity. On the contrary, the cage pocket shape has little effect on the sliding velocity between the ball and the cage pocket, thus the friction moment between the ball and the cage pocket is mainly affected by the pressure.

In order to study the sliding velocity distribution between the ball and the raceway, a schematic diagram of the ball/ raceway contact is drawn and the angular speed of ball gyroscopic motion $\omega_{\text {by }}$ is obtained, as shown in Figs. 17, 18 and 19, respectively. As Harris [29] pointed out that the speed of ball gyroscopic motion $\omega_{\text {by }}$ (less than $350 \mathrm{rad} / \mathrm{s}$ in this paper) to be very small compared with principal ball speed component $\omega_{\mathrm{bx}}$ (about $5000 \mathrm{rad} / \mathrm{s}$ in this paper) and relatively small compared to $\omega_{\mathrm{bz}}$ (about $2500 \mathrm{rad} / \mathrm{s}$ in this paper), however, the gyroscopic motion directly affects the sliding speed between the ball and the raceway. And in cylindrical pocket cage, the angular speed of ball gyroscopic motion $\omega_{\text {by }}$ are less than $75 \mathrm{rad} / \mathrm{s}$, while in the spherical pocket cage, the gyroscopic motion angular speed of ball $4 \#$ and ball $5 \#$ is close to $300 \mathrm{rad} / \mathrm{s}$, which explains the large friction moment caused by the sliding between the ball and the raceway in the spherical pocket cage bearing.

Figures 20 and 21 show the ball/cage contact force variation in all the pocket clearances of spherical pocket and cylindrical pocket cage, respectively. Obviously, in the spherical pocket cage, the ball/cage contact force is very stable, while in the cylindrical pocket cage, the ball/cage contact force is transient, and the peak of the contact force corresponds to the peak of the friction moment(shown in Fig. 16), indicating that the cage

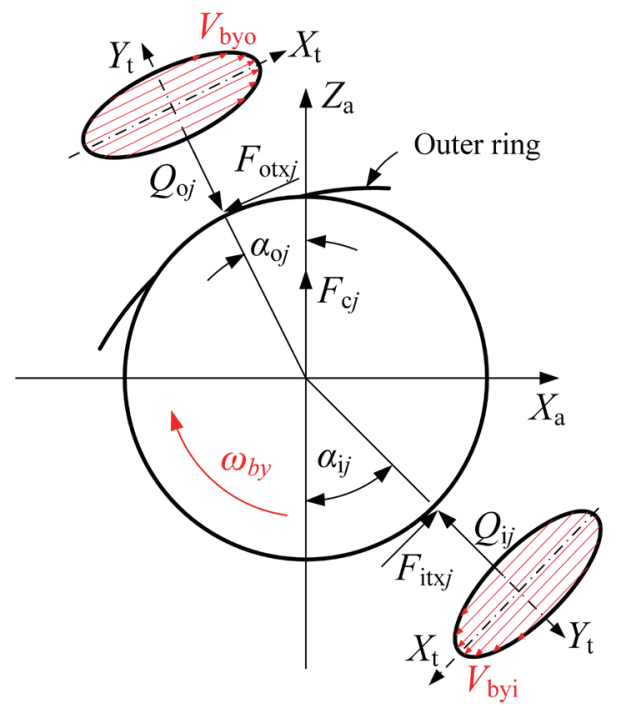

Fig. 17 Schematic diagram of the ball/raceway contact
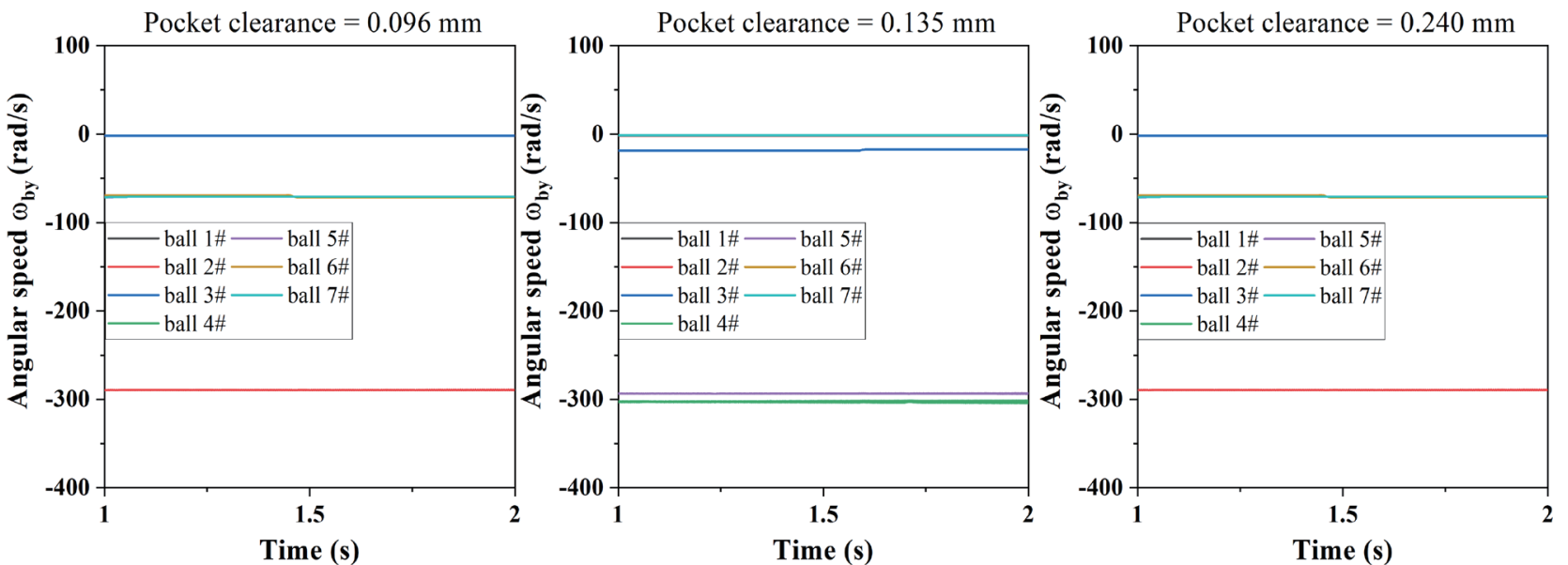

Fig. 18 Ball gyroscopic motion angular speed of spherical pocket cage 

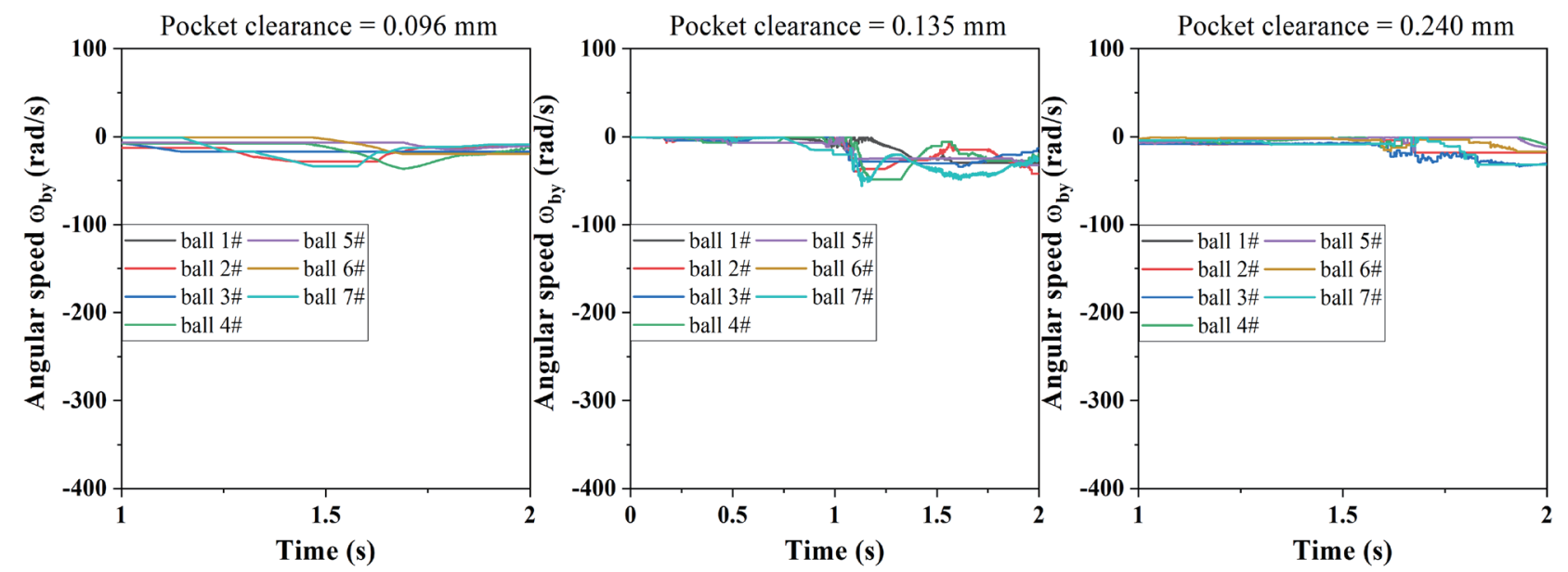

Fig. 19 Ball gyroscopic motion angular speed of cylindrical cage
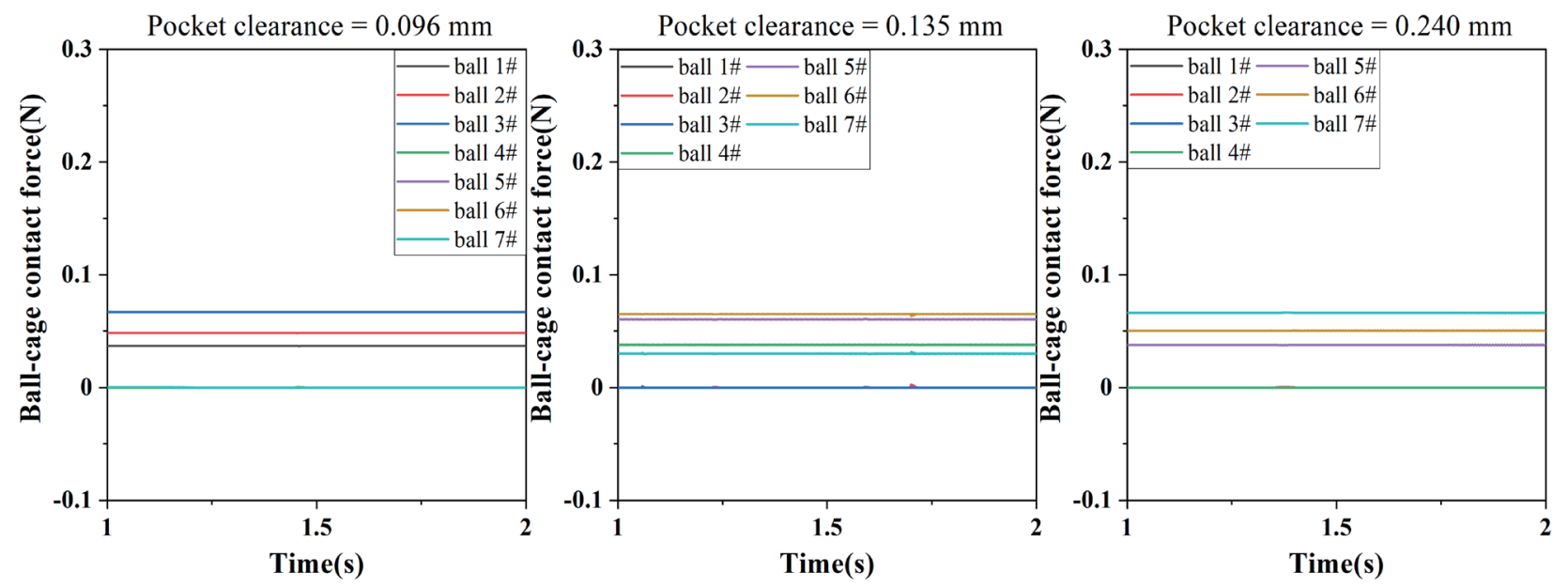

Fig. 20 Ball/cage contact force of spherical pocket cage
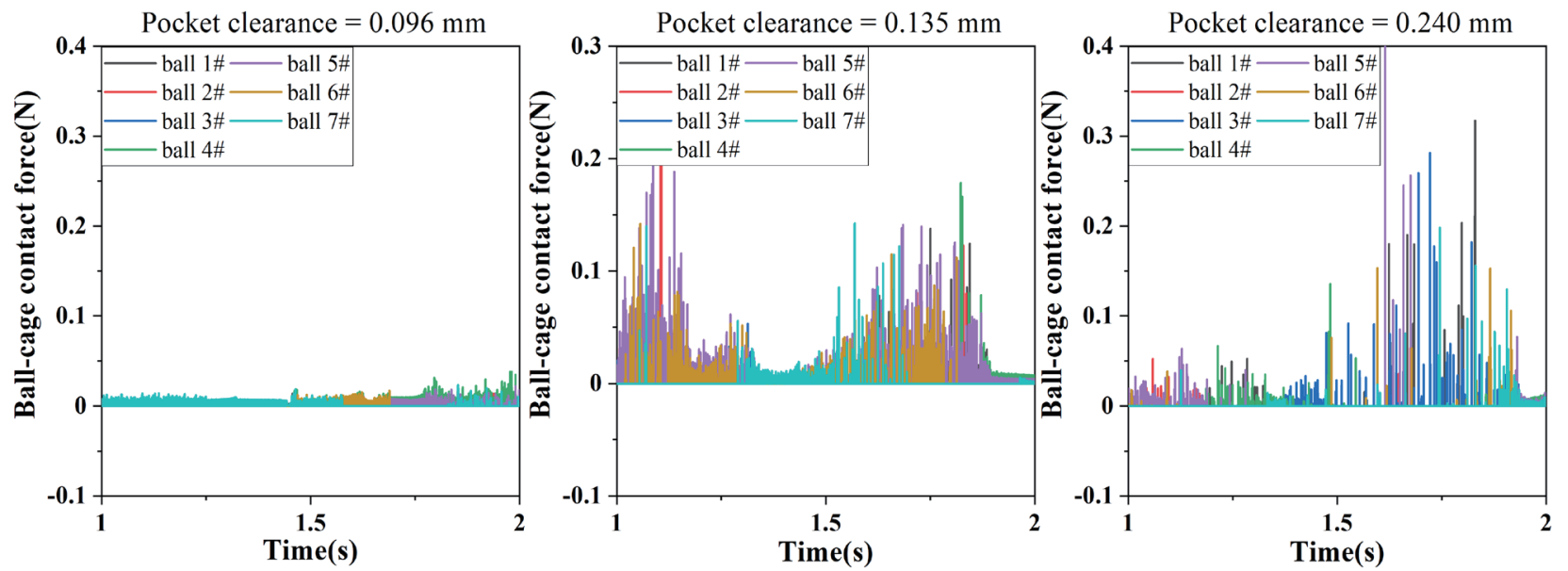

Fig. 21 Ball/cage contact force of cylindrical pocket cage

unstable motion and friction moment fluctuation is caused by the collision between the cage and the ball.

In addition, it can be found that when the cage pocket shape is spherical, there will be some balls in continuous contact with the cage, such as ball $4 \#$ and ball5\#, which is consistent with the result of Weinzapfel 's [11] spherical pocket cage. On the one hand, this kind of continuous contact will change the rotation axis of the ball and increase the velocity component in the direction of the gyro movement, resulting in an increase in the friction moment of the bearing. On the other hand, it also means 
that the force on the cage is very stable, and the movement stability of the cage is very good. On the contrary, the contact between the ball and the cylindrical pocket cage is transient, and the force between them is the collision impact force (this phenomenon can also be found in the results of many scholars, such as Gupta [16]), which makes the stability of the bearing friction moment and cage motion poor, but the average value of the friction moment is small.

\subsection{Comparison in different size bearings}

For generality, as shown in Table 2, three different sizes of bearings (the inner diameters of $1 \#, 2 \#$, and $3 \#$ bearings are $4 \mathrm{~mm}, 17 \mathrm{~mm}$, and $25 \mathrm{~mm}$, respectively) are selected, and the deviation ratio of whirl velocity and average friction moment of spherical pocket and cylindrical pocket cage in different bearings are obtained. It can be found that in the three bearings, the deviation ratio of spherical pocket cage whirl velocity is far less than the cylindrical pocket cage, indicating that the stability of the spherical pocket cage in the different size bearings is significantly better than the cylindrical pocket cage. When it goes to friction moment average, the friction moment of the spherical pocket cage is higher than that of the cylindrical pocket cage in different sizes of bearings. In addition, as the bearing size increases, the difference between the two pockets gradually decreases, which may indicate that the spherical pocket cage is more suitable for large bearings. In order to verify this law, the 4 \# bearing (the inner diameter is $100 \mathrm{~mm}$ ) was used for comparison and found to still conform to this law.

\section{Conclusion}

In this paper, the dynamic model of angular contact ball bearing with spherical pocket cage and the cylindrical pocket cage is established, and the reliability and correctness of the model are verified by experiments. Based on the model, the effects of the pocket shapes and the pocket clearance on the cage stability and the friction moment of the bearing are analysed. The following conclusions were made.

(1) The motion of spherical pocket cage is much more stable than that of the cylindrical pocket cage. In spherical pocket cage, the cage whirl orbit is a regular circle and whirl diameter is slightly smaller than the pocket clearance. While in the cylindrical pocket cage, as increasing the pocket clearance, and the whirl orbit changes from a regular circle to a polygonal shape and the cage is always guided by inner ring.

(2) The distribution of the ball is uneven in the two pockets, but steady in the spherical pocket cage. While in the cylindrical pocket cage, as the pocket clearance increases, the distribution stability of the ball gradually deteriorates, and the stability of the cage also deteriorates. Thus, the stability of the cage is positively related to the stability of the ball's distribution.

(3) The cage axial swing range is proportional to the angular distribution range of the ball/cage pocket collision point. In the spherical pocket cage, the angle of the ball/cage pocket collision point is stabilized at $0^{\circ}$ or $180^{\circ}$. However, in the cylindrical pocket cage, ball/cage pocket collision may occur at any angle.

(4) The bearing friction moment of the spherical pocket cage is larger than that of the cylindrical pocket cage, but the bearing friction moment of the cylindrical pocket cage is highly volatile. Furthermore, the bearing friction moment of the spherical pocket cage is mainly caused by the sliding between the ball and the inner and outer rings, which account for $40.3 \%$ and $35.5 \%$ respectively. In the cylindrical pocket, the fluctuation of the friction moment is mainly caused by the collision between the cage and the guiding ring and the steel ball.

In addition, it may be noted that the results of this paper are mainly for high-speed working conditions, and the results under low-speed conditions need to be further explored.

\section{Acknowledgments}

This work was carried out with financial support from the National twelfth five-year project of China for science and technology under Contract D.50-0109-15-001. The authors also gratefully acknowledge Tao Zhang, senior engineer of Bearing R \& D Center of Shanghai Prime Machinery Co. Ltd, for his encouragement and suggestions.

Table 2 Comparison in different size bearings

\begin{tabular}{|c|l|c|c|c|c|c|c|}
\hline \multirow{2}{*}{ Bearings } & \multirow{2}{*}{ Work condition } & \multicolumn{2}{|c|}{ Deviation ratio of whirl velocity } & \multicolumn{2}{c|}{ Friction moment average } \\
\cline { 3 - 8 } & $\begin{array}{c}\text { Spherical } \\
\text { pocket }\end{array}$ & $\begin{array}{c}\text { Cylindrical } \\
\text { pocket }\end{array}$ & $\begin{array}{c}\text { Spherical/ } \\
\text { Cylindrical }\end{array}$ & $\begin{array}{c}\text { Spherical } \\
\text { pocket(N.mm) }\end{array}$ & $\begin{array}{c}\text { Cylindrical } \\
\text { pocket(N.mm) }\end{array}$ & $\begin{array}{c}\text { Spherical/ } \\
\text { Cylindrical }\end{array}$ \\
\hline $1 \#^{*}$ & $\begin{array}{l}\mathrm{Fa}=7 \mathrm{~N} \\
\mathrm{~N}=30000 \mathrm{r} / \mathrm{min}\end{array}$ & $4.47 \times 10^{-4}$ & $5.83 \times 10^{-2}$ & $7.67 \times 10^{-3}$ & 0.114 & 0.018 & 6.33 \\
\hline $2 \#(7003)$ & $\begin{array}{l}\mathrm{Fa}=300 \mathrm{~N} \\
\mathrm{Ni}=20000 \mathrm{r} / \mathrm{min}\end{array}$ & $9.32 \times 10^{-4}$ & $4.82 \times 10^{-2}$ & $1.93 \times 10^{-2}$ & 19.03 & 4.32 & 4.41 \\
\hline $3 \#^{* *}$ & $\begin{array}{l}\mathrm{Fa}=1000 \mathrm{~N} \\
\mathrm{~N}=15000 \mathrm{r} / \mathrm{min}\end{array}$ & $1.46 \times 10^{-3}$ & $3.82 \times 10^{-2}$ & $4.32 \times 10^{-2}$ & 46.72 & 38.43 & 1.22 \\
\hline \multirow{2}{*}{$4 \#(7220)$} & $\begin{array}{l}\mathrm{Fa}=2000 \mathrm{~N} \\
\mathrm{~N}=10000 \mathrm{r} / \mathrm{min}\end{array}$ & $6.78 \times 10^{-4}$ & $4.3 \times 10^{-3}$ & $1.58 \times 10^{-1}$ & 235.82 & 198.64 & 1.19 \\
\hline
\end{tabular}

* Parameters of $1 \#$ bearing are shown in Table 1.

"*arameters of 3\# bearing are in Gupta's Ref [24]. 


\section{References}

[1] Kingsbury, E. P., "Torque Variations in Instrument Ball Bearings," ASLE Transactions, 8, 4, 1965, 435-441.

[2] Walters, C. T., "The Dynamics of Ball Bearings," Journal of Tribology, 93, 1, 1971, 1-10.

[3] Gupta, P. K., “Dynamics of Rolling-Element Bearings-Part III: Ball Bearing Analysis," Journal of Lubrication Technology, 1979, 101, 3, 312-318.

[4] Gupta, P. K., "Dynamics of Rolling-Element Bearings-Part IV: Ball Bearing Results," Journal of Lubrication Technology, 101, 3, 1979, 319-326.

[5] Gupta, P. K., Dill, J. F. and Bandow, H. E., “Dynamics of Rolling Element-Bearings Experimental Validation of the DREB and RAPIDREB Computer Programs," Journal of Tribology, 107, 1, 1985, 132-137.

[6] Meeks, C., "The Dynamics of Ball Separators in Ball Bearings-Part II: Results of Optimization Study," ASLE Transactions, 28, 3, 1985, 288295.

[7] Meeks, C. and Ng, K., "The Dynamics of Ball Separators in Ball Bearings-Part I: Analysis," ASLE Transactions, 28, 3, 1985, 277-287.

[8] Nogi, T., Maniwa, K. and Matsuoka, N., "A Dynamic Analysis of Cage Instability in Ball Bearings," Journal of Tribology, 140, 1, 2018, 011101.

[9] Niu, L. K., Cao, H. R., He, Z. and Li, Y. M., “An Investigation on the Occurrence of Stable Cage Whirl Motions in Ball Bearings Based on Dynamic Simulations," Tribology International, 103, 1, 2016, 12-24.

[10] Liu, X. H., Deng, S. E. and Teng, H. F., “Dynamic Stability Analysis of Cages in High-Speed Oil-Lubricated Angular Contact Ball Bearings," Transactions of Tianjin University, 17, 1, 2011, 20-27.

[11] Weinzapfel, N. and Sadeghi, F., "A Discrete Element Approach for Modeling Cage Flexibility in Ball Bearing Dynamics Simulations," Journal of Tribology, 131, 2, 2009, 021102.

[12] Ashtekar, A. and Sadeghi, F., "A New Approach for Including Cage Flexibility in Dynamic Bearing Models by Using Combined Explicit Finite and Discrete Element Methods," Journal of Tribology, 134, 4, 2012, 041502.

[13] Han, Q. K., Wen, B. G., Wang, M. and Deng, S. E., "Investigation of Cage Motions Affected by Its Unbalance in a Ball Bearing," Proceedings of the Institution of Mechanical Engineers Part K-Journal of Multi-Body Dynamics, 232, 2, 2018, 169-182.

[14] Ye, Z. Q. and Wang, L. Q., "Effect of External Loads on Cage Stability of High-Speed Ball Bearings," Proceedings of the Institution of Mechanical Engineers Part J-Journal of Engineering Tribology, 229, 11, 2015, 1300-1318.

[15] Bovet, C. and Zamponi, L., "An Approach for Predicting the Internal
Behaviour of Ball Bearings under High Moment Load," Mechanism and Machine Theory, 101, 1, 2016, 1-22.

[16] Gupta, P. K., "Frictional Instabilities in Ball Bearings," Tribology Transactions, 31, 2, 1988, 258-268.

[17] Wen, B. G., Ren, H. J., Zhang, H. and Han, Q. K., “Experimental Investigation of Cage Motions in an Angular Contact Ball Bearing," Proceedings of the Institution of Mechanical Engineers Part J-Journal of Engineering Tribology, 231, 8, 2017, 1041-1055.

[18] Chen, S. J., Chen, X. Y., Li, Q. Q. and Gu, J. M., “Experimental Study on Cage Dynamic Characteristics of Angular Contact Ball Bearing in Acceleration and Deceleration Process," Tribology Transactions, 2020, 1-12.

[19] Gupta, P. K., “Modeling of Instabilities Induced by Cage Clearances in Ball Bearings," Tribology Transactions, 34, 1, 1991, 93-99.

[20] Massimo, P. S., Giuseppe, N. and Wygachiewicz, M., "Analysis and Monitoring of Cage Dynamics in Ball Bearings for Space Applications," Proceedings of the ESMATS, 2017.

[21] Sathyan, K., Hsu, H. Y., Lee, S. H. and Gopinath, K., "LongTerm Lubrication of Momentum Wheels Used in Spacecrafts - An Overview," Tribology International, 43, 1-2, 2010, 259-267.

[22] Zhang, T., Chen X. Y., Gu, J. M. and Wang, Z. L., "Influences of Preload on the Friction and Wear Properties of High - Speed Instrument Angular Contact Ball Bearings," Chinese Journal of Aeronautics, 31, 3, 2018, 597-607.

[23] Chen, S. J., Chen, X. Y., Zhang, T., Li Q. Q. and Gu, J. M., “Cage Motion Analysis in Coupling Influences of Ring Guidance Mode and Rotation Mode," Journal of Advanced Mechanical Design, Systems, and Manufacturing, 13, 3, 2019, JAMDSM0054-JAMDSM0054.

[24] Gupta, P. K., "Advanced Dynamics of Rolling Elements," Springerverlag, 1984.

[25] Li, Q. Q., Chen, X. Y., Zhang T., Chen, S. J. and Gu, J. M., "Experimental Research on Cage Dynamic Characteristics of Angular Contact Ball Bearing," Mechanics \& Industry, 20, 2, 2019, $1-10$.

[26] Ghaisas, N., Wassgren, C. R. and Sadeghi, F. J., "Cage Instabilities in Cylindrical Roller Bearings," Journal of Tribology, 126, 4, 2004, 681689.

[27] Sakaguchi, T. and Harada, K. J., “Dynamic Analysis of Cage Behavior in a Tapered Roller Bearing," Journal of Tribology, 128, 3, 2006, 604-611.

[28] Houpert, L. J., "Ball Bearing and Tapered Roller Bearing Torque: Analytical, Numerical and Experimental Results," ASLE Transactions, 45, 3, 2002, 345-353.

[29] Harris, T. A. and Kotzalas, M. N., "Advanced Concepts of Bearing Technology: Rolling Bearing Analysis," CRC Press, 2006.

This paper is licensed under the Creative Commons Attribution-NonCommercial-NoDerivatives 4.0 International (CC BY-NC-ND 4.0) International License. This allows users to copy and distribute the paper, only upon conditions that (i) users do not copy or BY NC ND distribute such paper for commercial purposes, (ii) users do not change, modify or edit such paper in any way, (iii) users give
appropriate credit (with a link to the formal publication through the relevant DOI (Digital Object Identifier)) and provide a link to this license, and (iv) users acknowledge and agree that users and their use of such paper are not connected with, or sponsored, endorsed, or granted official status by the Licensor (i.e. Japanese Society of Tribologists). To view this license, go to https://creativecommons.org/licenses/by-nc-nd/4.0/. Be noted that the third-party materials in this article are not included in the Creative Commons license, if indicated on the material's credit line. The users must obtain the permission of the copyright holder and use the third-party materials in accordance with the rule specified by the copyright holder. 